\title{
Incidence and Risk of Hypertension in Cancer Patients Treated With Atezolizumab and Bevacizumab: A Systematic Review and Meta-Analysis
}

OPEN ACCESS

Edited by: John A. Rudd,

The Chinese University of Hong Kong, China

Reviewed by: Mounir Tilaoui, Waterford Institute of Technology, Ireland Lana Nezic,

University of Banja Luka, Bosnia and Herzegovina

${ }^{*}$ Correspondence: Jun $\mathrm{Li}$ ljadoctor@swmu.edu.cn Yaling $\mathrm{Li}$

lylapothecary@swmu.edu.cn

Specialty section: This article was submitted to Pharmacology of Anti-Cancer Drugs,

a section of the journal

Frontiers in Oncology

Received: 16 June 2021 Accepted: 22 September 2021 Published: 12 October 2021

Citation:

Jiang L, Tan X, Li J and Li Y (2021) Incidence and Risk of Hypertension in Cancer Patients

Treated With Atezolizumab and

Bevacizumab: A Systematic

Review and Meta-Analysis.

Front. Oncol. 11:726008. doi: 10.3389/fonc.2021.726008

\author{
Linhan Jiang ${ }^{1,2}$, Xiaoxia $\operatorname{Tan}^{1,2}$, Jun $\mathrm{Li}^{3^{*}}$ and Yaling $\mathrm{Li}^{1 *}$ \\ ${ }^{1}$ Department of Pharmacy, The Affiliated Hospital of Southwest Medical University, Luzhou, China, ${ }^{2}$ School of Pharmacy, \\ Southwest Medical University, Luzhou, China, ${ }^{3}$ Department of Anorectal, The Affiliated Hospital of Southwest Medical \\ University, Luzhou, China
}

Purpose: This study aims to inform previous clinical assessments to better understand the total risk of hypertension with atezolizumab and bevacizumab (hereafter referred to as "A-B") in cancer patients, and reduce future incidence of hypertension-related cardiovascular complications.

Methods: Databases, including PubMed, Embase, Cochrane, and Web of Science were searched to identify relevant studies, which were retrieved from inception to March 6, 2021. Studies focused on cancer patients treated with $A-B$ that provided data on hypertension were included. Statistical analyses were conducted to calculate hypertension incidence and relative risk (RR) with a random-effects or fixed-effects model, hinging on heterogeneity status.

Results: Ten studies including 2106 patients with renal cell carcinoma (RCC), hepatocellular carcinoma (HCC), ovarian cancer, anal cancer, neuroendocrine tumors (NETs), and cervical cancer were selected for this meta-analysis. For patients treated with A-B, the all-grade and high-grade (grade 3) hypertension incidence were 31.1\% (95\% Cl: 25.5-37.3) and $14.1 \%$ (95\% Cl: 10.9-18.1), respectively. No significant difference was observed in all-grade hypertension incidence between RCC and a non-RCC patients (32.9\% [95\% Cl: 25.3-42.6] v.s. 29.2\% [95\% Cl: 19.7-39.6)]). However, the number of high-grade hypertension incidence in RCC patients (9.4\% [95\% Cl: 4.1-21.3]) was lower than that of non-RCC patients (15.6\% [95\% Cl: 12.8-19.1]). RCC or HCC patients who received the A-B treatment were associated with significantly increased risk of all-grade hypertension with a RR of 7.22 (95\% Cl: 3.3-15.7; $p=0.6)$ compared with patients treated with atezolizumab. 


\begin{abstract}
Conclusions: Cancer Patients treated with atezolizumab and bevacizumab have a significantly increased risk of hypertension. Sufficient monitoring is highly recommended to prevent the consequences of treatment-induced hypertension and other cardiovascular complications.
\end{abstract}

Keywords: cancer, atezolizumab, bevacizumab, drug combination, hypertension

\section{INTRODUCTION}

Anti-vascular endothelial growth factor (VEGF) antibodies and programmed death 1 (PD-1)/programmed death ligand 1 (PD-L1) antibodies are novel and commonly used treatments for cancers (1, 2). Atezolizumab is a monoclonal immunoglobulin $\mathrm{G}$ antibody that binds to and inhibits the PD-L1 (3). Bevacizumab is a recombinant, humanized monoclonal blocking antibody specific for VEGF (4). The clinical activity of atezolizumab and bevacizumab (hereafter referred to as "A-B") was initially innovated in a phase Ib randomized clinical trial. It was discovered that the A-B combination improves antigen-specific $\mathrm{T}$-cell migration in metastatic RCC patients (5). Similarly, a phase II trial (IMmotion150) also showed improved progression-free survival in A-B-treated metastatic renal cell carcinoma (mRCC) patient expressing PD-L1 (6). A phase III clinical trial (IMmotion151) confirmed the aforementioned finding and showed a favorable safety profile (7). Additionally, A-B has clinical activity in unresectable hepatocellular carcinoma $(8,9)$. Currently, A-B has been approved by the United States Food and Drug Administration (FDA) for treating patients with advanced unresectable or metastatic HCC (10). In general, the purpose of the drug combination is to increase clinical efficacy and minimize drug resistance, offering a favorable therapeutic outcome. However, even though combination improves clinical efficacy, there is still uncertainty about whether the specific combination of A-B minimizes side effects.

Previously, A-B was shown to induce adverse effects including hypertension, proteinuria, fatigue, musculoskeletal pain, hyponatremia, infection, bowel obstruction, and nausea. In particular, hypertension is a major side effect, with its incidence ranging from $18.2 \sim 47.5 \%(11,12)$. The monitoring and treatment of hypertension are therefore crucial in managing side effects in patients treated with A-B, especially in RCC patients suffering from kidney dysfunction. In a phase Ib trial (GO30140) (9), a phase II trial (IMmotion 150) (6), and two phase III trials (IMbrave 150, IMmotion 151) $(7,8)$, proteinuria was more frequent in the A-B groups than the control. However, there is uncertainty about whether the combination of A-B showed a higher incidence of hypertension compared with monotherapy. There have been no reports or meta-analyses of the incidence of hypertension in patients treated with $\mathrm{A}-\mathrm{B}$ and the total risk of hypertension with A-B is unclear.

Given the increasing use of A-B in clinical applications, and the fact that hypertension, if not promptly recognized, can lead to major adverse cardiovascular events, we conducted a systematic review and meta-analysis to estimate the incidence and overall risk of hypertension with A-B among patients with cancer.

\section{METHODS}

This study followed the Preferred Reporting Items for Systematic reviews and Meta-Analyses (PRISMA) guidelines (13).

\section{Literature Search}

PubMed, Embase, Cochrane, and Web of Science were searched to identify published studies on the incidence and risk of hypertension in cancer patients treated with $\mathrm{A}+\mathrm{B}$. Studies were retrieved from inception to March 6, 2021, and no language restrictions or publication starting date limitations were applied. The search terms included atezolizumab, MPDL3280A, Tecentriq, Bevacizumab, Mvasi, Avastin, Neoplasms, Tumors, Hypertension, and related free words (Supplementary Material 1).

\section{Selection Criteria}

All published clinical trials and observational studies were included. Conference abstracts, reviews, individual cases, editorials, letters to the editor and publishers, concerning nonhuman studies, and other literature with unavailable study data were excluded. Relevant data were extracted independently by two reviewers, with differences reconciled by the third reviewer.

\section{Data Extraction}

Two reviewers performed independent double data extraction. The following information was obtained from each study: first author's name, year of publication, region, study design, trial phase, number of arms, treatment arms, number of patients enrolled, number of events or incidences of hypertension, median age, underlying malignancy (Table 1). The incidence of hypertension was calculated for the cumulative incidence. Allgrade and high-grade (grade 3) hypertension, as defined by 2018 ESC/ESH Clinical Practice Guidelines for the Management of Arterial Hypertension (17), were included in the analysis.

\section{Statistical Analysis Qualitative Synthesis}

The characteristics and quality of the included studies were assessed by two reviewers using the Newcastle-Ottawa scale (NOS) independently (18). Disagreements were resolved by discussion and further review.

\section{Quantitative Synthesis}

For this meta-analysis, both the fixed-effects and random-effects models were considered, hinging on the heterogeneity across included studies $(19,20)$. Significant heterogeneity was identified to exist when $p<0.1$ or $\mathrm{I}^{2}>50 \%(21)$. 
TABLE 1 | Characteristics of the trials and patients included in the meta-analysis.

\begin{tabular}{|c|c|c|c|c|c|c|c|c|c|c|c|c|}
\hline \multirow[t]{2}{*}{ Author } & \multirow[t]{2}{*}{ Year } & \multirow[t]{2}{*}{ Region } & \multirow{2}{*}{$\begin{array}{l}\text { Study } \\
\text { Design }\end{array}$} & \multirow[t]{2}{*}{ Phase } & \multirow[t]{2}{*}{ Arm } & \multirow{2}{*}{$\begin{array}{l}\text { Treatment } \\
\text { arms }\end{array}$} & \multirow{2}{*}{$\begin{array}{c}\text { Patients } \\
\text { enrolled, } \\
n\end{array}$} & \multirow{2}{*}{$\begin{array}{l}\text { Sample } \\
\text { size }\end{array}$} & \multicolumn{2}{|c|}{ Sex } & \multirow{2}{*}{$\begin{array}{l}\text { Median age, } \\
\text { years }\end{array}$} & \multirow[t]{2}{*}{ malignancy } \\
\hline & & & & & & & & & Women & Men & & \\
\hline $\begin{array}{l}\text { Moroney } \\
\text { et al. (14) }\end{array}$ & 2020 & USA & $\begin{array}{l}\text { Single } \\
\text { arm }\end{array}$ & $\mathrm{lb}$ & 1 & $A-B$ & 20 & 20 & $\begin{array}{c}20 \\
(100 \%)\end{array}$ & $\begin{array}{c}0 \\
(0 \%)\end{array}$ & 59 (37-80) & OC \\
\hline $\begin{array}{l}\text { Morris et al. } \\
\text { (15) }\end{array}$ & 2020 & USA & $\begin{array}{l}\text { Single } \\
\text { arm }\end{array}$ & $\|$ & 1 & $A-B$ & 20 & 20 & - & - & $59(43-80)$ & $\mathrm{AC}$ \\
\hline $\begin{array}{l}\text { McGregor } \\
\text { et al. (16) }\end{array}$ & 2020 & USA & $\begin{array}{l}\text { Single } \\
\text { arm }\end{array}$ & $\|$ & 1 & $A-B$ & 60 & 60 & $\begin{array}{c}13 \\
(22 \%)\end{array}$ & $\begin{array}{c}47 \\
(78 \%)\end{array}$ & 61 (22-82) & $\mathrm{RCC}$ \\
\hline $\begin{array}{l}\text { Lee et al. } \\
\text { (9) }\end{array}$ & 2020 & $\begin{array}{l}\text { USA, AUS, China, Japan, Korea, } \\
\text { New Zealand, Taiwan }\end{array}$ & $\mathrm{RCT}$ & $\mathrm{lb}$ & 2 & $\begin{array}{l}\text { A-B } \\
\text { Atezolizumab }\end{array}$ & 223 & 104 & $\begin{array}{c}20 \\
(19 \%)\end{array}$ & $\begin{array}{c}84 \\
(81 \%)\end{array}$ & 62 (23-82) & $\mathrm{HCC}$ \\
\hline $\begin{array}{l}\text { Halperin } \\
\text { et al. (12) }\end{array}$ & 2020 & USA & $\begin{array}{l}\text { Single } \\
\text { arm }\end{array}$ & $\|$ & 1 & $A-B$ & 40 & 40 & - & - & - & NETs \\
\hline $\begin{array}{l}\text { Friedman } \\
\text { et al. (11) }\end{array}$ & 2020 & USA & $\begin{array}{l}\text { Single } \\
\text { arm }\end{array}$ & $\|$ & 1 & $A-B$ & 11 & 11 & $\begin{array}{c}11 \\
(100 \%)\end{array}$ & $\begin{array}{c}0 \\
(0 \%)\end{array}$ & $48(31-55)$ & $\mathrm{CC}$ \\
\hline $\begin{array}{l}\text { Finn et al. } \\
\text { (8) }\end{array}$ & 2020 & $\begin{array}{l}\text { USA, AUS, Canada, China, } \\
\text { Czechia, France, Germany, Hong } \\
\text { Kong, Italy, Japan, Korea, } \\
\text { Poland, Russia, Singapore, } \\
\text { Spain, Taiwan, UK }\end{array}$ & RCT & III & 2 & $\begin{array}{l}\text { A-B } \\
\text { Sorafenib }\end{array}$ & 501 & 336 & $\begin{array}{c}109 \\
(18 \%)\end{array}$ & $\begin{array}{c}227 \\
(82 \%)\end{array}$ & $64(56-71)$ & HCC \\
\hline $\begin{array}{l}\text { Rini et al. } \\
(7)\end{array}$ & 2019 & $\begin{array}{l}\text { USA, AUS, Bosnia and } \\
\text { Herzegovina, Brazil, Canada, } \\
\text { Czechia, Denmark, France, } \\
\text { Germany, Italy, Japan, Korea, } \\
\text { Mexico, Poland, Russia, } \\
\text { Singapore, Spain, Taiwan, } \\
\text { Thailand, Turkey, UK }\end{array}$ & RCT & III & 2 & $\begin{array}{l}\text { A-B } \\
\text { Sunitinib }\end{array}$ & 915 & 454 & $\begin{array}{c}137 \\
(30 \%)\end{array}$ & $\begin{array}{c}317 \\
(70 \%)\end{array}$ & $62(56-69)$ & RCC \\
\hline $\begin{array}{l}\text { McDermott } \\
\text { et al. (6) }\end{array}$ & 2018 & $\begin{array}{l}\text { USA, Czechia, France, Germany, } \\
\text { Italy, Poland, Romania, Spain, UK }\end{array}$ & $\mathrm{RCT}$ & $\|$ & 3 & $\begin{array}{l}\text { A-B } \\
\text { Atezolizumab } \\
\text { Sunitinib }\end{array}$ & 305 & 101 & $\begin{array}{c}27 \\
(27 \%)\end{array}$ & $\begin{array}{c}74 \\
(73 \%)\end{array}$ & 62 (32-88) & RCC \\
\hline $\begin{array}{l}\text { Wallin et al. } \\
\text { (5) }\end{array}$ & 2016 & USA & $\begin{array}{l}\text { Single } \\
\text { arm }\end{array}$ & $\mathrm{lb}$ & 1 & $A-B$ & 11 & 10 & 3 (27\%) & $\begin{array}{c}8 \\
(73 \%)\end{array}$ & $59(42-74)$ & RCC \\
\hline
\end{tabular}

RCT, randomized controlled trial; A-B, atezolizumab, and bevacizumab; -, not available; OC, ovarian cancer; AC, anal cancer; RCC, renal cancer carcinoma; HCC, hepatocellular carcinoma; NETs, neuroendocrine tumors; CV, cervical cancer.

\section{Sources of Bias}

Publication bias was evaluated by visual inspection of funnel plots and with both the Begg's and Egger's tests.

\section{Heterogeneity Analysis}

The $Q$ tests and $\mathrm{I}^{2}$ index were estimated to quantified heterogeneity.

\section{Statistical Software}

All statistical analyses were performed with $\mathrm{R}$ software (version 4.0.2). A $p$ value $\leq 0.05$ was considered significant.

\section{RESULTS}

\section{Data Extraction And Quality Assessment Systematic Review Process}

A total of 811 studies were identified, of which 390 were removed owing to duplication or overlap (determined using Endnote software). Another 266 studies were excluded with screening titles and abstracts. Out of the remaining 155 full-text studies, 104 were excluded. Ultimately, 10 studies were eligible for analysis. Figure $\mathbf{1}$ shows a flow chart depicting the process of publication selection.

\section{Quality Assessment With the Newcastle-Ottawa Scale}

To evaluate the quality of the evidence, the Newcastle-Ottawa quality assessment scale was used. According to the NewcastleOttawa Scale, all selected studies achieved at least 6 stars, indicating a low to moderate risk of bias (Supplementary Table 1).

\section{Characteristics of Eligible Studies}

In total, 2106 patients were eligible for analysis, and 1156 patients were treated with A-B, versus 950 patients treated with other treatments included atezolizumab, sorafenib, and sunitinib. The characteristics of the included studies are shown in Table 1. All studies were interventional clinical trials, with 10 studies including 4 randomized controlled trials and 6 singlearm trials. There was no mention of preexisting hypertension in all trials. The underlying malignancies included RCC, HCC, ovarian cancer, anal cancer, neuroendocrine tumors (NETs), and cervical cancer. The dose and schedule of A-B was $1200 \mathrm{mg}$ of atezolizumab plus $15 \mathrm{mg}$ per kilogram of body weight of bevacizumab intravenously every 3 weeks in all trials.

\section{Evidence Synthesis}

\section{The Overall Incidence of Hypertension}

Data regarding all-grade hypertension were available for analysis from 8 trials including 1107 patients who had various tumors and received A-B. The all-grade hypertension incidence ranged from 


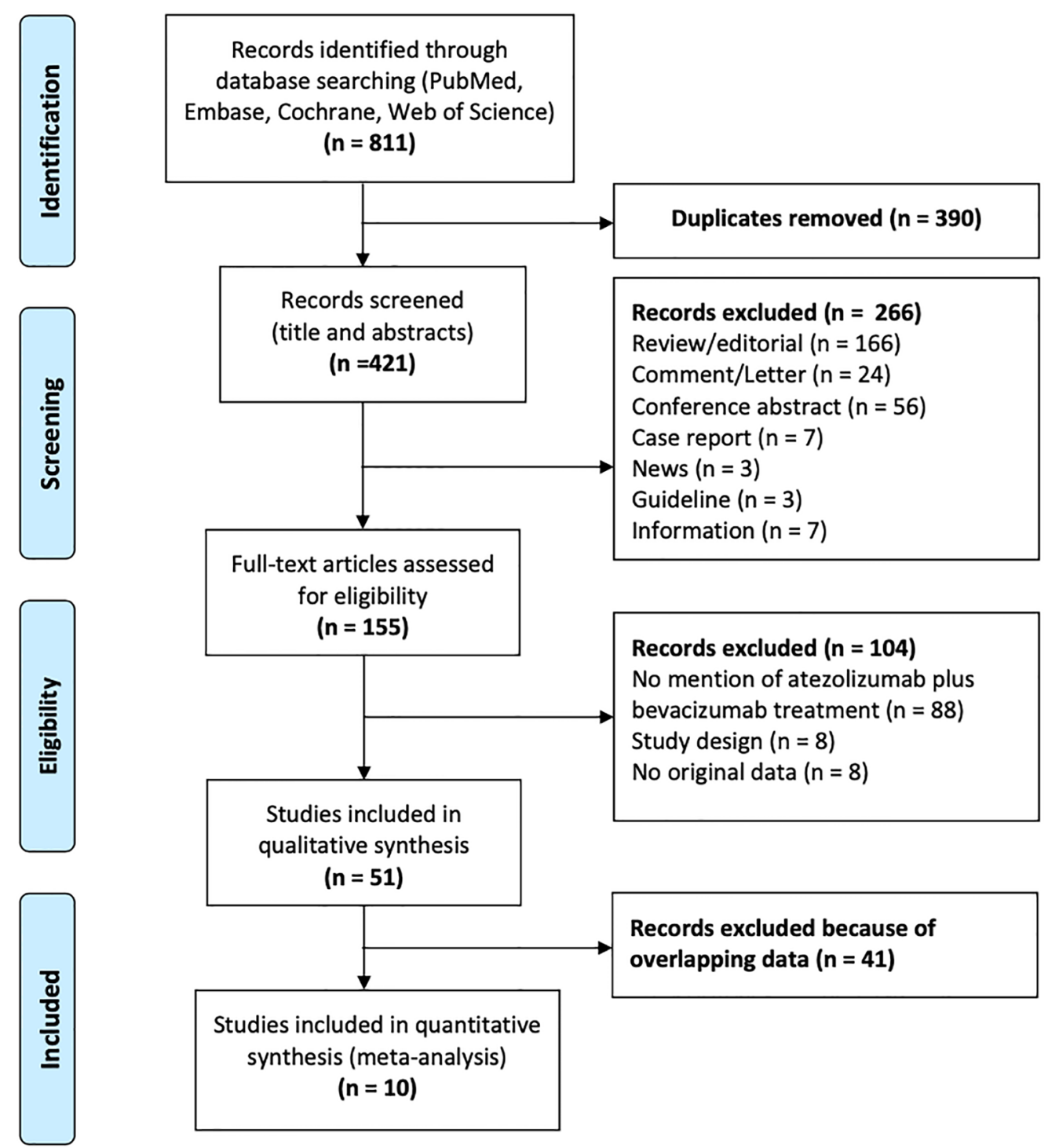

FIGURE 1 | Flow chart of the selection of publications included in the meta-analysis.

$18.2 \%$ to $47.5 \%$, with the lowest incidence noted in an advanced cervical cancer clinical trial (11), and the highest in an advanced neuroendocrine tumor clinical trial (12). The heterogeneity statistic showed significance across the studies included in the meta-analysis $\left(I^{2}=66 \%, p<0.01\right)$. We performed a sensitivity analysis conducted in which any single study was excluded by turn to explore the source of heterogeneity. The results did not change significantly, proposing the robustness of these findings (Supplementary Figure 1). As analyzed by a random-effects model, the all-grade hypertension incidence in patients treated with A-B was 31.1\% (95\% CI: 25.5-37.3; Figure 2A).

High-grade hypertension cannot be controlled with monotherapy that otherwise leads to life-threatening consequences, resulting in adverse effects or even A-B discontinuation. Data regarding high-grade hypertension were assessable for analysis from 10 trials, which included 1147 patients. The grade 3 hypertension incidence ranged between $0 \%$ and $27.3 \%$, with the lowest in the advanced cervical cancer trial (11), and highest in the metastatic renal cell carcinoma trial (5). The heterogeneity of the included studies was $I^{2}=44 \%(p<$ $0 \cdot 01$ ). A sensitivity analysis was performed to explore the source of heterogeneity and the results were robust (Supplementary

Figure 1). As analyzed by the random-effects model, the summary estimate for the incidence of high-grade hypertension was 14.1\% (95\% CI: 10.9-18.1; Figure 2B).

\section{Incidence of Hypertension in RCC and Non-RCC}

RCC patients are more burdened by hypertension due to previous renal parenchymal disease and renal insufficiency and sufficient evidence demonstrating that hypertension predisposes 
them to renal cell cancer development (22). In addition, among the 2106 patients included in the analysis, $61 \%$ had RCC. As such, further analysis of the hypertension incidence in RCC patients compared with non-RCC patients is required. Using the random-effects model (considerable heterogeneity, $I^{2}=64 \%$, $\left.p=0.04 ; I^{2}=76 \%, p<0.01\right)$, the incidence of all-grade and high-grade hypertension was 32.9\% (95\% CI: 25.3-42.6) and 9.4\% (95\% CI: 4.1-21.3) respectively in RCC patients (Figure 3). The all-grade and high-grade hypertension incidence were $29.2 \%$ (95\% CI: 19.7-39.6) and 15.6\% (95\% CI: 12.8-19.1) respectively in non-RCC patients, as determined by the random-effects model (considerable heterogeneity, $I^{2}=69 \%, p=0.02$ ) in allgrade and fixed-effects model (no heterogeneity, $I^{2}=0 \%$, $p=0.84$ ) in high-grade hypertension (Figure 4). All results did not significantly change by sensitivity analysis, hence proposing the robustness of these findings (Supplementary Figure 1). No significant difference was detected in the all-grade hypertension incidence (RR 1.14[95\% CI 0.95-1.36]) and high-grade hypertension incidence (RR 0.78 [95\% CI 0.58-1.05]) between RCC and non-RCC patients.

\section{RR of Hypertension}

The summary RR for hypertension with A-B compared with the control group in HCC or RCC patients was done among the 1908 patients from four randomized controlled trials. Two trials used atezolizumab as the control, and the other used sorafenib or sunitinib. In addition to a trial for RCC (40.1\%) (7), hypertension with lower incidence in the control group $(1.7 \%, 20.2 \%$ and $24.4 \%$, respectively) $(6,8,9)$. In conclusion, no evidence was found of an association between A-B and a significantly increased risk of hypertension compared with control (RR 1.36 [95\% CI 0.812.29]; Figure 5). The heterogeneity statistic showed significance across the studies included in the meta-analysis $\left(I^{2}=87 \%, p<0.01\right)$. Thus, we performed a sensitivity analysis and the results proposed the robustness of these findings (Supplementary Figure 1). To better understand the possible reasons for the heterogeneity, we then performed subgroup analyses by drug type. In the atezolizumab subset, the incidence of hypertension was statistically higher among patients on A-B therapy (RR 7.22 [95\% CI 3.3-15.7]; Supplementary Figure 2). As a consequence, A-B was associated with a significantly increased risk of hypertension in patients compared with atezolizumab.

\section{Publication Bias}

No significant publication bias was indicated for all-grade hypertension and high-grade hypertension by either the Egger's test ( $p=0.72$ and 0.40 , respectively) or the Begg's test ( $p=0.46$ and 0.33 , respectively). The funnel plots, Egger's test, and Begg's test are provided in Supplementary Figures 3-5.

\section{DISCUSSION}

In 2019, more than 16.9 million Americans with a history of cancer were alive, and this number is projected to grow to more than 22.1 million by 2030 (23). The development of novel anticancer drugs has significantly contributed to increased survival rates for patients with cancer over recent decades and comes at the cost of potential short-term and long-term toxicities (24). Cardiovascular toxicity is nonnegligible and adversely

A
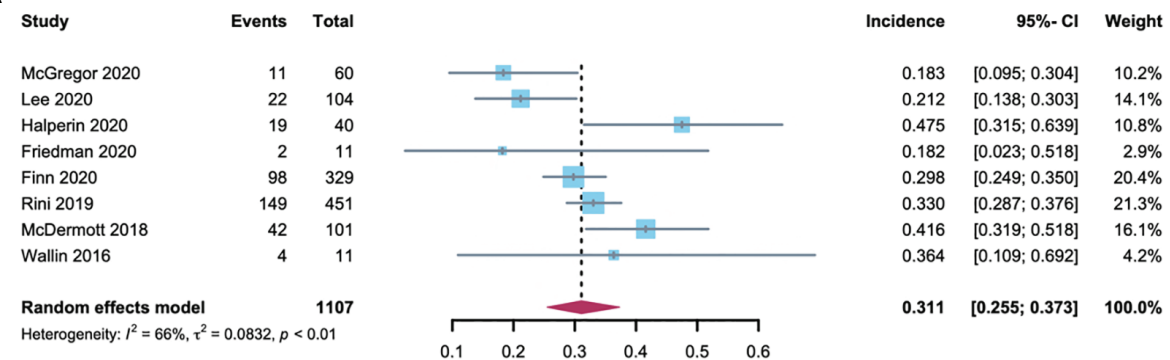

B

$\begin{array}{lrr}\text { Study } & \text { Events } & \text { Total } \\ \text { Moroney 2020 } & 3 & 20 \\ \text { Morris 2020 } & 2 & 20 \\ \text { McGregor 2020 } & 2 & 60 \\ \text { Lee 2020 } & 15 & 104 \\ \text { Halperin 2020 } & 8 & 40 \\ \text { Friedman 2020 } & 0 & 11 \\ \text { Finn 2020 } & 50 & 329 \\ \text { Rini 2019 } & 63 & 451 \\ \text { McDermott 2018 } & 4 & 101 \\ \text { Wallin 2016 } & 3 & 11 \\ & & \\ \text { Random effects model } & & 1147 \\ \text { Heterogeneity: } l^{2}=44 \%, \tau^{2}=0.0552, p=0.06\end{array}$
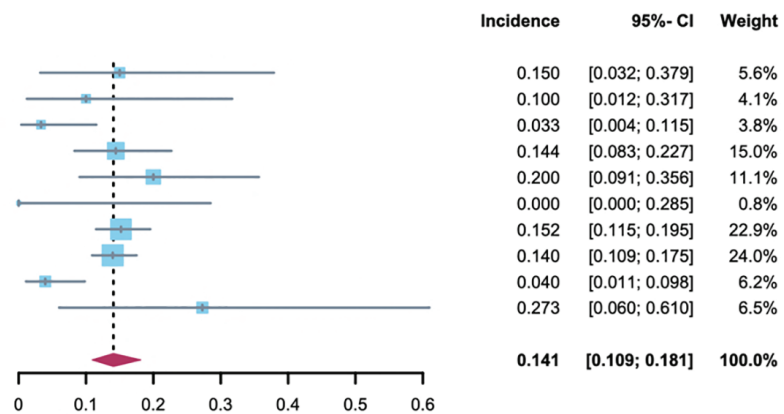

FIGURE 2 | Forest plot of hypertension incidence in cancer patients treated with (A, B). (A) incidences of all-grade hypertension; (B) incidences of high-grade hypertension. 

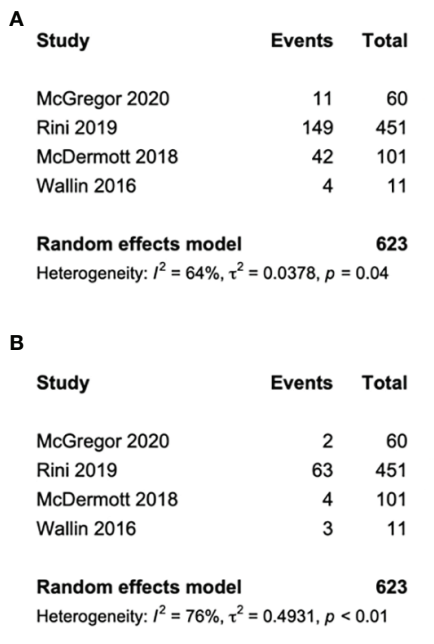
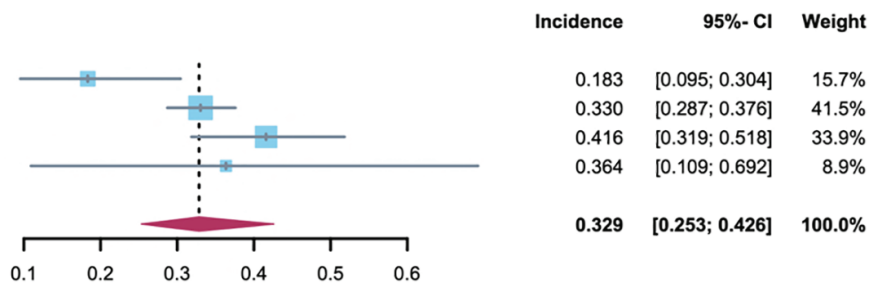

$$
\text { 95\%-Cl Weight }
$$$$
0.033 \quad[0.004 ; 0.115] \quad 17.9 \%
$$$$
0.140 \quad[0.109 ; 0.175] \quad 34.5 \%
$$$$
0.040 \quad[0.011 ; 0.098] \quad 23.8 \%
$$$$
0.273 \quad[0.060 ; 0.610] \quad 23.8 \%
$$

$0.094 \quad[0.041 ; 0.213] \quad 100.0 \%$

FIGURE 3 | Forest plot of the A-B-associated hypertension incidence in RCC patients. (A) incidences of all-grade hypertension with RCC; (B) incidences of highgrade hypertension with RCC.

A

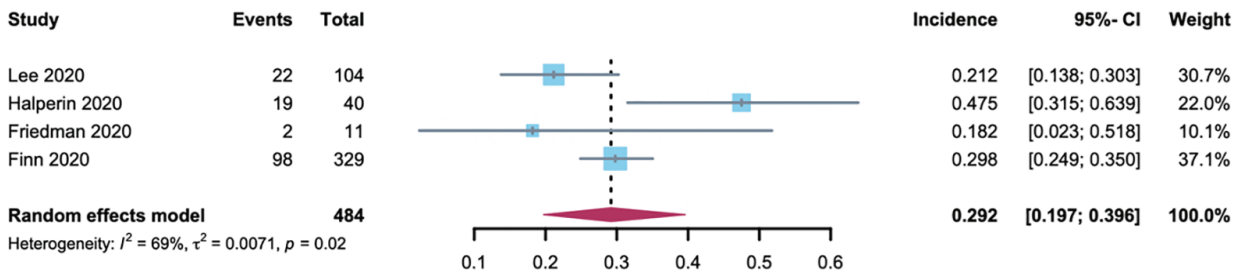

B

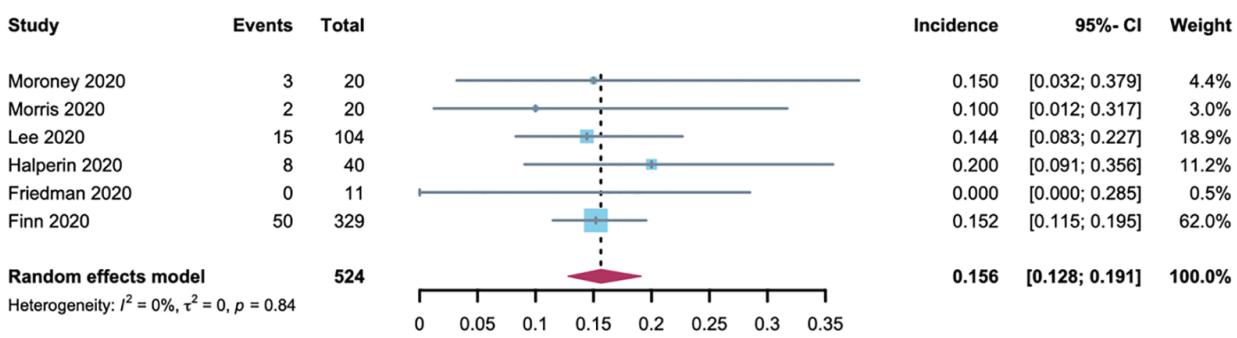

FIGURE 4 | Forest plot of the A-B-associated hypertension incidence in non-RCC patients. (A) incidences of all-grade hypertension with non-RCC; (B) incidences of high-grade hypertension with non-RCC.

affects outcomes (25). Hypertension is an important risk factor for cardiovascular diseases and a serious global problem. The prevalence of hypertension has doubled in the past three decades, accounting for 8.5 million deaths annually worldwide $(26,27)$. More importantly, Hypertension was the most common comorbidity among patients with cancer in a large observational cohort study, with a reported prevalence of $38 \%$ (28). As understanding of targeted therapies improves, there is growing awareness of the importance and detrimental vascular effects of a new generation of antitumor agents $(29,30)$. In this study, we performed a meta-analysis of the incidence and risk of hypertension in cancer patients treated with A-B. These findings have important clinical implications for quantifying the risks of hypertension in considering the trade-off of A-B treatment during shared decision-making.

Solid tumors are angiogenesis-dependent for growth and metastases. Currently, several proangiogenic factors have been identified, among which VEGF is a critical mediator that promotes angiogenesis (31). Anti-VEGF therapy was demonstrated a significant antitumor effect, leading to the rapid development of the VEGF signaling pathway (VSP) inhibitors, which are an approved treatment of a broad 


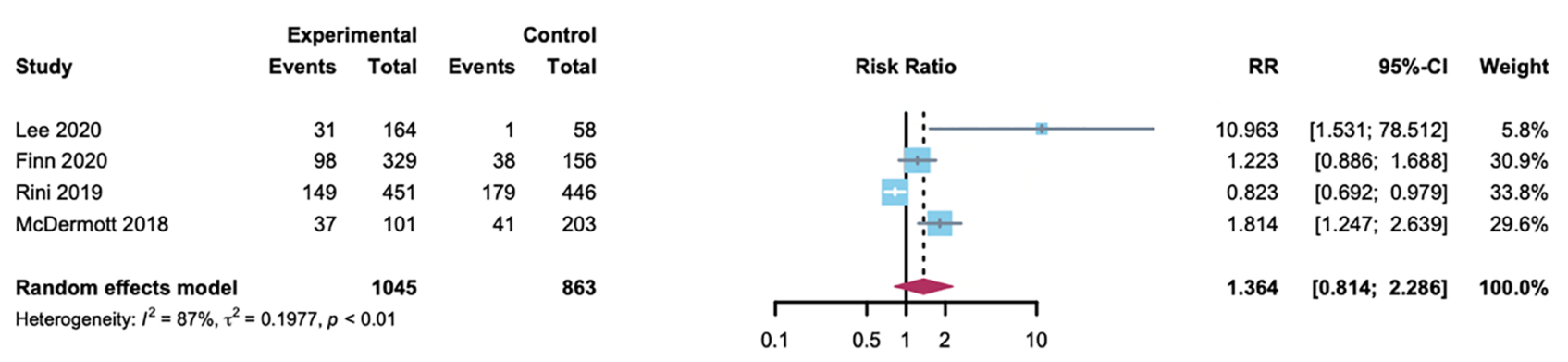

FIGURE 5 | The RR of atezolizumab plus bevacizumab-associated hypertension versus control.

spectrum of malignancies. However, wide clinical application of VSP inhibitors is accompanied by increasing incidence of cardiovascular risk, and increasing hypertension, arterial or venous thrombotic events, and heart failure (32). Hypertension associated with anti-programmed death-1 agents and angiogenesis inhibitors is an issue that cannot be ignored in patients receiving A-B therapy. In addition to atezolizumab, several other anti-programmed death-1 agents, such as durvalumab and avelumab appear to correlate with the genesis of hypertension (Table 2). Likewise, apart from bevacizumab, other angiogenesis inhibitors such as sorafenib, sunitinib, cediranib, ramucirumab, and apatinib are also associated with hypertension (Table 3). In a study by Abdel-Qadir and colleagues, angiogenesis inhibitors were demonstrated to be corrected with hypertension incidence of $22.1 \%$ and an OR of 5.28 [95\%CI: 4.53-6.15] (40). Our study demonstrates that A-B appears to correlate with a significantly increased risk of hypertension incidence of $31.1 \%$ (95\% CI: 25.5-37.3) and an RR of 7.22 (95\% CI: 3.3-15.7; $p=0.6$ ) compared with atezolizumab in a subset that included patients with RCC or HCC. Thus, when considered these findings together, A-B was significantly associated with a considerable risk of hypertension in RCC, HCC, ovarian cancer, anal cancer, NETs, and cervical cancer.

At present, the mechanisms of hypertension have not been fully understood. However, many possible mechanisms have been proposed. One of the key mechanisms by which VEGF signaling pathway inhibitors mediate hypertension is through acute inhibition of endothelial-derived vasodilatory factors such as nitric oxide (NO) (41). Activation of VEGF induces rapid hypotension, through upregulating NO synthase by PI3k/Akt and MAPK dependent pathways in endothelial cells, which promotes NO production, vascular permeability, and vascular vasodilation.

TABLE 2 | Hypertension risk with programmed death ligand 1 (PD-L1) antibodies.

\begin{tabular}{lcccc}
\hline $\begin{array}{c}\text { Molecular } \\
\text { target }\end{array}$ & $\begin{array}{c}\text { Incidence of } \\
\text { hypertension }\end{array}$ & $\begin{array}{c}\text { Relative risk of } \\
\text { hypertension }\end{array}$ & Reference \\
\hline Atezolizumab & PD-L1 & $0 \%-19 \%$ & - & $(9,33-35)$
\end{tabular}

PD-L1, programmed death ligand 1; -, not available.

*durvalumab plus ramucirumab, durvalumab plus olaparib/cediranib, and velumab plus axitinib associated with hypertension.
Treatment with VSP inhibitors has been demonstrated to decrease NO synthesis and lead to hypertension (42). Other mechanisms include rarefaction, a process of impaired angiogenesis in normal, nontumor tissue, and neurohormonal activation, or the renin angiotensin aldosterone system (RASS), which likely play roles (43). The association of A-B with hypertension might be directly correlated to the inhibition of bevacizumab on the vascular endothelial growth factor receptor (VEGFR).

Hypertension was independently related to RCC risk, which can either be an independent risk factor for RCC as a result of chronic renal hypoxia and angiogenesis or RCC patients might have an increased risk of hypertension due to previous renal parenchymal disease and renal dysfunction $(44,45)$. Our study showed that the all-grade hypertension incidence in RCC patients $(32.9 \%$ [95\% CI: 25.3-42.6]) is higher than non-RCC patients (29.2\% [95\% CI: 19.7-39.6]) when they are treated with A-B; however, the high-grade hypertension incidence in RCC patients (9.4\% [95\% CI: 4.1-21.3]) is lower than those with nonRCC (15.6\% [95\% CI: 12.8-19.1]). A possible explanation that might account for these findings is that the A-B has elevated blood pressure and induced hypertension prominently so that the difference between RCC and non-RCC becomes unapparent. It is upheld by the observation that a high incidence in all-grade hypertension with A-B (31.1\% [95\% CI: 25.5-37.3]) was noted in this study. Another explanation is that A-B are mainly metabolized by the liver $(46,47)$. Previous nephrectomy and RCC-related renal insufficiency might not have a substantial potential effect on the concentration of A-B.

Hypertension is mainly caused by bevacizumab and several opinion managements of bevacizumab-associated hypertension applied on A-B treatment perhaps are available. According to the drug label information for bevacizumab, there is a higher incidence of severe hypertension in patients who received bevacizumab compared with those who received chemotherapy. Across clinical studies, with high-grade hypertension incidence was $5 \sim 18 \%$, and monitoring of blood pressure is needed biweekly or every 3 weeks during the treatment of A-B (46). Thereafter, hypertension should be treated with appropriate antihypertensive therapy and regular monitoring. Blood pressure should also be monitored regularly in patients with bevacizumab-induced or -exacerbated hypertension after discontinuing. Discontinuation in cases of patients not fully controlled by medication, 
TABLE 3 | Hypertension risk with angiogenesis inhibitors.

\begin{tabular}{|c|c|c|c|c|}
\hline & Molecular target & $\begin{array}{l}\text { Incidence of } \\
\text { hypertension }\end{array}$ & $\begin{array}{c}\text { Relative risk of } \\
\text { hypertension }\end{array}$ & Reference \\
\hline Bevacizumab & Anti-VEGF-A antibody & $25.4 \%(21.3-30.1)$ & $7.5(4.2-13.4)$ & (36) \\
\hline Sorafenib & B-Raf, FLT-1, FLT-3, FLT-4, KDR, KIT, PDGFR-A, PDGFR-B, FGFR, c-fms & $22.5 \%(19.5-25.9)$ & $3.9(2.6-5.9)$ & $(37)$ \\
\hline Sunitinib & ABL-1, c-KIT, PDGFR-A, PDGFR-B, FLT-1, KDR, FLT-3, FLT-4, FGFR, SRC, c-smc & $29 \%$ & - & (38) \\
\hline Ramucirumab & Anti-KDR antibody & $21.3 \%$ & $2.7(2.3-3.2)$ & (39) \\
\hline
\end{tabular}

VEGF, anti-vascular endothelial growth factor; -, not available; VEGFR, vascular endothelial growth factor receptor; PDGFR, platelet-derived growth factor receptor.

hypertensive crisis, or hypertensive encephalopathy (46). According to this study, all-grade hypertension incidence is (31.1\% [95\% CI: 25.5-37.3]) and high-grade hypertension is $14.1 \%$ (10.9-18.1), and perhaps similar monitoring, control, and treatment deserve consideration. Based on the recommendations of the European Society of Cardiology (ESC), angiotensin converting enzyme inhibitors (ACEI), angiotensin receptor blockers (ARBs), and dihydropyridine calcium channel blockers (CCBs) have been recommended as first-line treatments (43). Otherwise, beta-blockers may also be taken into account due to their effects on NO and vasodilation. Additionally, salt restriction might prevent VEGF inhibitor-induced toxicity since VEGF inhibitor-induced hypertension is salt-sensitive (48).

Drug interactions are also a significant concern for cancer patients. In a previous study, after 4 cycles of therapy (at Day 63), 3 out of 8 patients who received bevacizumab with paclitaxel and carboplatin had lower paclitaxel exposure than initiation (Day 0). In comparison, patients who received paclitaxel and carboplatin had a better paclitaxel exposure at Day 63 compared with Day 0. Fortunately, the current study shows that no potential drug-drug interactions are presented in atezolizumab. Likewise, there are no interactions of bevacizumab in other drugs. When bevacizumab was administered in combination with irinotecan or SN38, interferon- $\alpha$, carboplatin, or paclitaxel, no clinically significant interaction on the pharmacokinetics was observed (46).

Many risk factors may also have additive effects on hypertension in patients with cancer. As the most frequent comorbidity among patients with cancer, hypertension has a relatively high proportion among those with preexisting hypertension, older age, and high body mass index (28). Several agents have also been shown to induce or aggravate previously controlled hypertension. As discussed previously, VEGF is the drug class that exhibits the strongest association with hypertension in most relevant randomized trials (49). Other anticancer therapies linked to hypertension include cisplatin derivatives, proteasome inhibitors, corticosteroids, alkylating agents, interferon-alpha, radiation therapy, inhibitors of the mammalian target of rapamycin (mTOR inhibitors), taxanes, vinca rosea alkaloids, and gemcitabine (50). Nonantineoplastic agents, on the other hand, include immunosuppressive agents (cyclosporine, tacrolimus), erythropoietin, and nonsteroidal anti-inflammatory drugs (NSAIDs) (50). In terms of disease, aside from renal cell carcinoma, which may cause hypertension bidirectionally (51), hypertension is evident among patients with hepatocellular carcinoma and paraneoplastic syndrome (52). In addition, it is worth noting that hypertension may be due to white-coat hypertension or a reactive anxiety disorder. It is of great importance to investigate the patient's history, and undertake ECG and echocardiography or Holter ambulatory $\mathrm{BP}$ monitoring (ABPM), to avoid prescribing drugs were not necessary (53).

The strengths of the study include that it represents the first meta-analysis of cancer patients treated with A-B, including 2106 patients, with 1156 patients assigned A-B. Furthermore, most of the included trials are multinational and multicentric. In addition, we sought to explore the sources of heterogeneity observed in studies through subgroup analysis by comparing different drug types. In addition, the statistical test showed no indication of potential publication bias based on our confirmation, as we attempted to diminish bias by contacting corresponding authors.

Several limitations deserve comment in our systematic review and meta-analysis. Firstly, like any other meta-analysis, our study is affected by the limitations of the included clinical trials. These trials might have underestimated A-B-associated hypertension incidence due to the imperfection of a study by Morris and colleagues (15) recording adverse events. Additionally, patients with significant cardiovascular disease, inadequately controlled hypertension, prior history of hypertensive crisis or hypertensive encephalopathy, and other cardiovascular-related abnormalities have been excluded from some studies. Therefore, the capacity for determining the overall incidence of hypertension is limited. In contrast, the baseline of hypertension was not mentioned in the included clinical trials. The omission may have contributed to an overestimation of hypertension incidence with A-B. Secondly, the cancer patients in our study were all screened from randomized clinical trials. Therefore, our findings were concluded largely from academic centers and research institutes and might not be representative of community-treated cancer patients. Thirdly, although we have concluded that there is no significant difference in hypertension incidence between RCC and non-RCC patients treated with A-B, our finding might be restricted to a small sample size of high-grade hypertension patients. Finally, the included studies showed heterogeneity in study design, population demographics, duration of follow-up, and measurement and adjustment for confounders. Despite the use of appropriate random-effect models and subgroup analyses, these differences are not explained.

This study demonstrated that the drug combination does not only not reduce side effects, it also causes more adverse reactions, and the combination of A-B is associated with an increased risk of hypertension. Sufficient monitoring and earlier administration could be considered as ways to prevent the consequences of treatment-induced hypertension and other cardiovascular 
complications. Further trials of A-B will be needed due to the limitations of our study, and more surveillance and reporting of the hypertensive and cardiovascular events are required to identify the individual and optimal therapeutic approach of hypertension with A-B.

\section{DATA AVAILABILITY STATEMENT}

The original contributions presented in the study are included in the article/Supplementary Material. Further inquiries can be directed to the corresponding authors.

\section{AUTHOR CONTRIBUTIONS}

LJ, XT, JL, and YL designed the study. LJ and XT identified eligible studies, assessed quality of the included studies, extracted

\section{REFERENCES}

1. Apte RS, Chen DS, Ferrara N. VEGF in Signaling and Disease: Beyond Discovery and Development. Cell (2019) 176(6):1248-64. doi: 10.1016/ j.cell.2019.01.021

2. Havel JJ, Chowell D, Chan TA. The Evolving Landscape of Biomarkers for Checkpoint Inhibitor Immunotherapy. Nat Rev Cancer (2019) 19(3):133-50. doi: 10.1038/s41568-019-0116-x

3. Akinleye A, Rasool Z. Immune Checkpoint Inhibitors of PD-L1 as Cancer Therapeutics. J Hematol Oncol (2019) 12(1):92. doi: 10.1186/s13045-019-0779-5

4. Garcia J, Hurwitz HI, Sandler AB, Miles D, Coleman RL, Deurloo R, et al. Bevacizumab (Avastin ${ }^{\circledR}$ ) in Cancer Treatment: A Review of 15 Years of Clinical Experience and Future Outlook. Cancer Treat Rev (2020) 86:102017. doi: 10.1016/j.ctrv.2020.102017

5. Wallin JJ, Bendell JC, Funke R, Sznol M, Korski K, Jones S, et al. Atezolizumab in Combination With Bevacizumab Enhances Antigen-Specific T-Cell Migration in Metastatic Renal Cell Carcinoma. Nat Commun (2016) 7:12624. doi: 10.1038/ncomms12624

6. Mcdermott DF, Huseni MA, Atkins MB, Motzer RJ, Rini BI, Escudier B, et al. Clinical Activity and Molecular Correlates of Response to Atezolizumab Alone or in Combination With Bevacizumab Versus Sunitinib in Renal Cell Carcinoma. Nat Med (2018) 24(6):749-57. doi: 10.1038/s41591-018-0053-3

7. Rini BI, Powles T, Atkins MB, Escudier B, Mcdermott DF, Suarez C, et al. Atezolizumab Plus Bevacizumab Versus Sunitinib in Patients With Previously Untreated Metastatic Renal Cell Carcinoma (IMmotion151): A Multicentre, Open-Label, Phase 3, Randomised Controlled Trial. Lancet (2019) 393 (10189):2404-15. doi: 10.1016/S0140-6736(19)30723-8

8. Finn RS, Qin S, Ikeda M, Galle PR, Ducreux M, Kim TY, et al. Atezolizumab Plus Bevacizumab in Unresectable Hepatocellular Carcinoma. N Engl J Med (2020) 382(20):1894-905. doi: 10.1056/NEJMoa1915745

9. Lee MS, Ryoo BY, Hsu CH, Numata K, Stein S, Verret W, et al. Atezolizumab With or Without Bevacizumab in Unresectable Hepatocellular Carcinoma (GO30140): An Open-Label, Multicentre, Phase 1b Study. Lancet Oncol (2020) 21(6):808-20. doi: 10.1016/S1470-2045(20)30156-X

10. Casak SJ, Donoghue M, Fashoyin-Aje L, Jiang X, Rodriguez L, Shen YL, et al. FDA Approval Summary: Atezolizumab Plus Bevacizumab for the Treatment of Patients With Advanced Unresectable or Metastatic Hepatocellular Carcinoma. Clin Cancer Res (2021) 27(7):1836-41. doi: 10.1158/10780432.CCR-20-3407

11. Friedman CF, Snyder Charen A, Zhou Q, Carducci MA, Buckley De Meritens A, Corr DR, et al. Phase II Study of Atezolizumab in Combination With Bevacizumab in Patients With Advanced Cervical Cancer. I Immunother Cancer (2020) 8(2):e001126. doi: 10.1136/jitc-2020-001126

12. Halperin DM, Liu S, Dasari A, Fogelman DR, Bhosale P, Mahvash A, et al. A Phase II Trial of Atezolizumab and Bevacizumab in Patients With Advanced, data and performed data analyses. LJ, XT, JL, and YL wrote and revised the manuscript. All authors contributed to the article and approved the submitted version.

\section{FUNDING}

This work was supported by the National Natural Science Foundation of China (81803019).

\section{SUPPLEMENTARY MATERIAL}

The Supplementary Material for this article can be found online at: https://www.frontiersin.org/articles/10.3389/fonc.2021. 726008/full\#supplementary-material

Progressive Neuroendocrine Tumors (NETs). J Clin Oncol (2020) 38 (4_suppl):619-9. doi: 10.1200/JCO.2020.38.4_suppl.619

13. Liberati A, Altman DG, Tetzlaff J, Mulrow C, Gøtzsche PC, Ioannidis JP, et al. The PRISMA Statement for Reporting Systematic Reviews and Meta-Analyses of Studies That Evaluate Healthcare Interventions: Explanation and Elaboration. BMJ (2009) 339:b2700. doi: 10.1136/ bmj.b2700

14. Williams B, Mancia G, Spiering W, Agabiti Rosei E, Azizi M, Burnier M, et al. Safety and Clinical Activity of Atezolizumab Plus Bevacizumab in Patients With Ovarian Cancer: A Phase Ib Study. Clin Cancer Res (2020) 26(21):56317. doi: 10.1158/1078-0432.CCR-20-0477

15. Morris V, Liu S, Johnson B, Prasad S, Mahvash A, Bhosale P, et al. 403MO Atezolizumab in Combination With Bevacizumab for Patients With Unresectable/Metastatic Anal Cancer. Ann Oncol (2020) 31(S4):S412. doi: 10.1016/j.annonc.2020.08.514

16. Mcgregor BA, Mckay RR, Braun DA, Werner L, Gray K, Flaifel A, et al. Results of a Multicenter Phase II Study of Atezolizumab and Bevacizumab for Patients With Metastatic Renal Cell Carcinoma With Variant Histology and/ or Sarcomatoid Features. J Clin Oncol (2020) 38(1):63-70. doi: 10.1200/ JCO.19.01882

17. Williams B, Mancia G, Spiering W, Agabiti Rosei E, Azizi M, Burnier M, et al. 2018 ESC/ESH Guidelines for the Management of Arterial Hypertension: The Task Force for the Management of Arterial Hypertension of the European Society of Cardiology (ESC) and the European Society of Hypertension (ESH). Eur Heart J (2018) 39 (33):3021-104. doi: 10.1093/eurheartj/ehy339

18. Ga Wells BS, O'connell D, Peterson J, Welch V, Losos M, Tugwell P. The Newcastle-Ottawa Scale (NOS) for Assessing the Quality of Nonrandomized Studies in Meta-Analyses. Canada: Department of Epidemiology and Community Medicine, University of Ottawa (2014). Available at: http:// www.ohri.ca/programs/clinical_epidemiology/oxford.asp.

19. Lewis S, Clarke M. Forest Plots: Trying to See the Wood and the Trees. Bmj (2001) 322(7300):1479-80. doi: 10.1136/bmj.322.7300.1479

20. Dersimonian R, Laird N. Meta-Analysis in Clinical Trials. Control Clin Trials (1986) 7(3):177-88. doi: 10.1016/0197-2456(86)90046-2

21. Lau J, Ioannidis JP, Schmid CH. Quantitative Synthesis in Systematic Reviews. Ann Intern Med (1997) 127(9):820-6. doi: 10.7326/0003-4819-127-9199711010-00008

22. Feldman DR, Baum MS, Ginsberg MS, Hassoun H, Flombaum CD, Velasco S, et al. Phase I Trial of Bevacizumab Plus Escalated Doses of Sunitinib in Patients With Metastatic Renal Cell Carcinoma. J Clin Oncol (2009) 27 (9):1432-9. doi: 10.1200/JCO.2008.19.0108

23. Miller KD, Nogueira L, Mariotto AB, Rowland JH, Yabroff KR, Alfano CM, et al. Cancer Treatment and Survivorship Statistics, 2019. CA Cancer J Clin (2019) 69(5):363-85. doi: 10.3322/caac.21565 
24. Van Dorst DCH, Dobbin SJH, Neves KB, Herrmann J, Herrmann SM, Versmissen J, et al. Hypertension and Prohypertensive Antineoplastic Therapies in Cancer Patients. Circ Res (2021) 128(7):1040-61. doi: 10.1161/ CIRCRESAHA.121.318051

25. Moslehi JJ. Cardiovascular Toxic Effects of Targeted Cancer Therapies. N Engl $J$ Med (2016) 375(15):1457-67. doi: 10.1056/NEJMra1 100265

26. NCD Risk Factor Collaboration (NCD-RisC). Worldwide Trends in Hypertension Prevalence and Progress in Treatment and Control From 1990 to 2019: A Pooled Analysis of 1201 Population-Representative Studies With 104 Million Participants. Lancet (2021) 398(10304):957-80. doi: 10.1016/S0140-6736(21)01330-1

27. Zhou B, Perel P, Mensah GA, Ezzati M. Global Epidemiology, Health Burden and Effective Interventions for Elevated Blood Pressure and Hypertension. Nat Rev Cardiol (2021) S1:1-18. doi: 10.1038/s41569-021-00559-8

28. Piccirillo JF, Tierney RM, Costas I, Grove L, Spitznagel EL Jr. Prognostic Importance of Comorbidity in a Hospital-Based Cancer Registry. JAMA (2004) 291(20):2441-7. doi: 10.1001/jama.291.20.2441

29. Neves KB, Montezano AC, Lang NN, Touyz RM. Vascular Toxicity Associated With Anti-Angiogenic Drugs. Clin Sci (Lond) (2020) 134 (18):2503-20. doi: 10.1042/CS20200308

30. Guha A, Armanious M, Fradley MG. Update on Cardio-Oncology: Novel Cancer Therapeutics and Associated Cardiotoxicities. Trends Cardiovasc Med (2019) 29(1):29-39. doi: 10.1016/j.tcm.2018.06.001

31. Fukumura D, Kloepper J, Amoozgar Z, Duda DG, Jain RK. Enhancing Cancer Immunotherapy Using Antiangiogenics: Opportunities and Challenges. Nat Rev Clin Oncol (2018) 15(5):325-40. doi: 10.1038/nrclinonc.2018.29

32. Li M, Kroetz DL. Bevacizumab-Induced Hypertension: Clinical Presentation and Molecular Understanding. Pharmacol Ther (2018) 182:152-60. doi: 10.1016/j.pharmthera.2017.08.012

33. De Azevedo SJ, De Melo AC, Roberts L, Caro I, Xue C, Wainstein A, et al. First-Line Atezolizumab Monotherapy in Patients With Advanced BRAF (V600) Wild-Type Melanoma. Pigment Cell Melanoma Res (2021) 34(5):9737. doi: $10.1111 / \mathrm{pcmr} .12960$

34. Moore KN, Bookman M, Sehouli J, Miller A, Anderson C, Scambia G, et al. Atezolizumab, Bevacizumab, and Chemotherapy for Newly Diagnosed Stage III or IV Ovarian Cancer: Placebo-Controlled Randomized Phase III Trial (IMagyn050/GOG 3015/ENGOT-Ov39). J Clin Oncol (2021) 39(17):1842-55. doi: 10.1200/JCO.21.00306

35. Sternberg CN, Loriot Y, James N, Choy E, Castellano D, Lopez-Rios F, et al. Primary Results from SAUL, A Multinational Single-Arm Safety Study of Atezolizumab Therapy for Locally Advanced or Metastatic Urothelial or Nonurothelial Carcinoma of the Urinary Tract. Eur Urol (2019) 76(1):7381. doi: 10.1016/j.eururo.2019.03.015

36. Zhu X, Wu S, Dahut WL, Parikh CR. Risks of Proteinuria and Hypertension With Bevacizumab, An Antibody Against Vascular Endothelial Growth Factor: Systematic Review and Meta-Analysis. Am J Kidney Dis (2007) 49 (2):186-93. doi: 10.1053/j.ajkd.2006.11.039

37. Wu S, Chen JJ, Kudelka A, Lu J, Zhu X. Incidence and Risk of Hypertension With Sorafenib in Patients With Cancer: A Systematic Review and MetaAnalysis. Lancet Oncol (2008) 9(2):117-23. doi: 10.1016/S1470-2045(08) 70003-2

38. SUTENT- Sunitinib Malate Capsule. Pfizer Laboratories Div Pfizer Inc. Available at: https://www.sutent.com 2021 Pfizer Inc. All rights reserved. June 2021.

39. Arnold D, Fuchs CS, Tabernero J, Ohtsu A, Zhu AX, Garon EB, et al. MetaAnalysis of Individual Patient Safety Data From Six Randomized, PlaceboControlled Trials With the Antiangiogenic VEGFR2-Binding Monoclonal Antibody Ramucirumab. Ann Oncol (2017) 28(12):2932-42. doi: 10.1093/ annonc/mdx514

40. Abdel-Qadir H, Ethier JL, Lee DS, Thavendiranathan P, Amir E. Cardiovascular Toxicity of Angiogenesis Inhibitors in Treatment of Malignancy: A Systematic Review and Meta-Analysis. Cancer Treat Rev (2017) 53:120-7. doi: 10.1016/j.ctrv.2016.12.002
41. Humphreys BD, Atkins MB. Rapid Development of Hypertension by Sorafenib: Toxicity or Target? Clin Cancer Res (2009) 15(19):5947-9. doi: 10.1158/1078-0432.CCR-09-1717

42. Nazer B, Humphreys BD, Moslehi J. Effects of Novel Angiogenesis Inhibitors for the Treatment of Cancer on the Cardiovascular System: Focus on Hypertension. Circulation (2011) 124(15):1687-91. doi: 10.1161/ CIRCULATIONAHA.110.992230

43. Versmissen J, Mirabito Colafella KM, Koolen SLW, Danser AHJ, et al. Vascular Cardio-Oncology: Vascular Endothelial Growth Factor Inhibitors and Hypertension. Cardiovasc Res (2019) 115(5):904-14. doi: 10.1093/cvr/ cvz022

44. Capitanio U, Bensalah K, Bex A, Boorjian SA, Bray F, Coleman J, et al. Epidemiology of Renal Cell Carcinoma. Eur Urol (2019) 75(1):74-84. doi: 10.1016/j.eururo.2018.08.036

45. Oparil S, Acelajado MC, Bakris GL, Berlowitz DR, Cífková R, Dominiczak AF, et al. Hypertension. Nat Rev Dis Primers (2018) 4:18014. doi: 10.1038/ nrdp.2018.14

46. AVASTIN- Bevacizumab Injection, Solution. Genentech, Inc. Available at: https://dailymed.nlm.nih.gov/dailymed/drugInfo.cfm?setid=939b5d1f-9fb24499-80ef-0607aa6b114e\#section-7 Genentech, Inc.Updated January 25, 2021.

47. TECENTRIQ- Atezolizumab Injection, Solution. Genentech, Inc. Available at: https://dailymed.nlm.nih.gov/dailymed/drugInfo.cfm?setid=6fa682c9-a3124932-9831-f286908660ee\#modal-label-archives. Genentech, Inc. Updated April 19, 2021.

48. Lankhorst S, Baelde HJ, Clahsen-Van Groningen MC, Smedts FM, Danser AH, Van Den Meiracker AH, et al. Effect of High Salt Diet on Blood Pressure and Renal Damage During Vascular Endothelial Growth Factor Inhibition With Sunitinib. Nephrol Dial Transplant (2016) 31(6):914-21. doi: 10.1093/ ndt/gfv 410

49. Maitland ML, Bakris GL, Black HR, Chen HX, Durand JB, Elliott WJ, et al. Initial Assessment, Surveillance, and Management of Blood Pressure in Patients Receiving Vascular Endothelial Growth Factor Signaling Pathway Inhibitors. J Natl Cancer Inst (2010) 102(9):596-604. doi: 10.1093/jnci/djq091

50. Katsi V, Magkas N, Georgiopoulos G, Athanasiadi E, Virdis A, Masi S, et al. Arterial Hypertension in Patients Under Antineoplastic Therapy: A Systematic Review. J Hypertens (2019) 37(5):884-901. doi: 10.1097/HJH.0000000000002006

51. Stojanovic M, Goldner B, Ivkovic D. Renal Cell Carcinoma and Arterial Hypertension. Clin Exp Nephrol (2009) 13(4):295-9. doi: 10.1007/s10157-0080122-x

52. Arai H, Saitoh S, Matsumoto T, Makita F, Mitsugi S, Yuasa K, et al. Hypertension as a Paraneoplastic Syndrome in Hepatocellular Carcinoma. J Gastroenterol (1999) 34(4):530-4. doi: 10.1007/s005350050309

53. Tini G, Sarocchi M, Tocci G, Arboscello E, Ghigliotti G, Novo G, et al. Arterial Hypertension in Cancer: The Elephant in the Room. Int J Cardiol (2019) 281:133-9. doi: 10.1016/j.ijcard.2019.01.082

Conflict of Interest: The authors declare that the research was conducted in the absence of any commercial or financial relationships that could be construed as a potential conflict of interest.

Publisher's Note: All claims expressed in this article are solely those of the authors and do not necessarily represent those of their affiliated organizations, or those of the publisher, the editors and the reviewers. Any product that may be evaluated in this article, or claim that may be made by its manufacturer, is not guaranteed or endorsed by the publisher.

Copyright (c) 2021 Jiang, Tan, Li and Li. This is an open-access article distributed under the terms of the Creative Commons Attribution License (CC BY). The use, distribution or reproduction in other forums is permitted, provided the original author(s) and the copyright owner(s) are credited and that the original publication in this journal is cited, in accordance with accepted academic practice. No use, distribution or reproduction is permitted which does not comply with these terms. 